\title{
Application of Chemistry by the Municipality*
}

\author{
Some of the Many Places Where a Knowledge of Chemistry is Essential
}

\author{
By Hermann W. Mahr $\dagger$
}

Chemistry has for the last decade been a valuable aid in securing the health and well-being of the dweller in American cities. Its fields of activity have been the inspection of foods, the all-important duty of controlling the quality of the water supply and the disposal of sewage. Beyond this, science has only in rare instan

In the meantime chemistry has been becoming important factor in the industrial field. Chemists have improved processes and brought forth new products, many of which are finding wide use in civic housekeeping. The position now occupied by applied chemistry has led the far-seeing to herald the near future as the age of chemistry. With the advance in the industrial field have come additions to the knowledge and improvements in the methods of the science which now enable it to successfully attack special problems confronting our cities.

The chemists at present engaged in the all-important work of aiding in the conserving of the public health are often too well occupied with their duties to give time or attention to the technical problems which arise. Municipal engineers attempt to solve these questions, but are handicapped by a lack of knowledge of industrial chemistry and the ability to think chemically. These conditions give rise to opportunities for the chemist to aid the engineer and become his active co-worker. Members of the profession entering this work must necessarily be well acquainted with the processes of applied chemistry, and the methods of analysis and testing of industrial products, particularly the materials of engineering.

Our Federal Government has been a pioneer in this respect and its researches have redounded to its materia advantage. It now has in its service well-informed experts in many branches of industrial chemistry. The results of their investigations have been published, and many of them are invaluable to the municipality. The latter should have in its service chemists able to apply the results of these Governmental and of other technical investigations to the problems of the city.

A large portion of the expenditure of the municipa corporation is for the purchase of supplies. The value of the chemical laboratory in connection with this work has long been recognized. Some of our railroads were the first organizations to avail themselves of scientific supervision and inspection in this connection. The Federa Government has followed their lead and carried on the work through the Contracts Laboratory and similar testing stations in the large departments.

The first duty of the chemist concerned with the pur chase of supplies is the inspection of materials delivered. Study of the various commodities and the framing of requirements is second only to the work of testing. Many proprietary compounds, of supposedly secret composition, with alleged wonderful properties, are urged on purchasing officials. On being subjected to chemical analysis these materials often prove to be composed of cheap ingredients for which a price greatly in excess of their value is asked.

The fuel bill of the municipality is probably the largest item of its budget for supplies. Competitive bidding, in accordance with well-drawn specifications, has been universally adopted among large coal buyers as the best solution of the problem. In spite of its manifest advantages, city officials have hitherto been backward in putting a purchasing method of this nature into operation. The chemist can aid here greatly by studying the composition and heat value of the available coal supplies, drawing up requirements and testing shipments.

His labor in relation to fuel should, however, extend to overseeing its proper and economical use. The importance of the fuel question has, within recent years, assumed such proportions that chemists designated as fuel engineering chemists now make a specialty of the subject of fuel burning. A chemist, in municipal service, devoting himself to the wider application of chemistry, can make profitable studies of the methods of coal burn-
can can make profitable studies of the methods of coal burn-
ing in schools and other public buildings. Wasteful grates may be found which require changes in the size of coal, and possibly expensive coals are burned where cheaper grades would adequately and economically furnish the required heat. Poor methods of stoking often allow opportunities for improvement with consequent allow

Closely connected with the fuel question is that of obtaining proper boiler water. This part of municipal *Reprinted from the Journal of Industrial and Engineering Chemistry.

† Of the Standard Testing Laboratory of the Board of Estimate and Apportionment of thc City of New York housekeeping is often entirely neglected, with a resulting increased consumption of fuel and decreased life of th heating or power apparatus. In some cases the man in charge is persuaded to buy a solution of sal soda and soda lye for a price many times in excess of its value. This water in question. An examination of the water supply from the feed water standpoint will reveal the causes of trouble and enable the chemist to prescribe an inexpensive compound or the proper method of treatment.

There are many commodities purchased in large amounts whose composition is well enough known for them to be bought on specifications and subjected to test. One of the chief of these materials is soap, the cost of which is a considerable part of the amount expended for supplies. The Federal Government and railoads have long bought soap on well-drawn requirements.

Within recent years the fact that "there is paper and papers" has been recognized. Large concerns are now paying attention to the quality of this material. The paper experts of the German Government have made investigations and devised tests and methods of analysi for ascertaining the value of various papers. The use of these methods have become known and are taken advantage of in the paper trade and by large users. Ou municipalities are among the latter and can gain mat
rially by scientifically scrutinizing paper supplies.

Rubber hose is an expensive necessity purchased in considerable amounts. On its quality and strength much depends. This has led insurance underwriters to requir that hose for use in insured buildings be of the highes grade. Inspection of rubber requires it to be subjected to thorough chemical analysis and severe chemical tests. Cities should demand and make certain that hose for use by their fire departments and in public buildings is of the best quality.

Construction work of various kinds consumes a large portion of the civic bank credit. To obtain lasting structures and roads and prevent the use of inferio materials, the latter must be continually examined. Iron and steel should be subjected to chemical and microscopical analysis. Cements require chemical as well as physical tests. Results obtained by the chemist on a concrete containing one part cement to twelve of aggregate instead of one to six, will often furnish grounds for civil or criminal action against an unscrupulous contractor. The waterproofing of concrete has occupied the attention of the engineer and technologist within the las few years. The importance of the subject has resulted in the appearance of many worthless waterproofing compounds whose nature and value can be best revealed by chemical analysis.

Paints and protective coatings have been investigated to good effect by our American chemists, and their result have put this subject on a scientific basis. An understanding of these principles and knowledge of the properties of paints is necessary for the adequate protection of municipal buildings and structures.

Modern traffic conditions have been instrumental in bringing more of the products of applied chemistry into use by the city than any other influence. The ingenuity and experience of the oil and coal tar chemists have been drawn upon to solve the problems arising from the use of the automobile. Various forms of pavement with permanent bituminous binders have come into wider use. The manufacture of new asphalts from oils in order to supplement the natural deposits owes its impetus to the demand thus created. Treatment of coal tar for use in tar macadam and as a semi-permanent surface binder has occupied the attention of the chemical technologist for the same reason. The lighter tar and oil products have also been studied and experimented with in the effort to produce dust preventives. - Treated wood block pavements are meeting with increased favor. Upon a knowl edge of the properties of various treating media and thorough inspection and testing rests the success of these pavements and the comfort of those compelled to use

The city is called upon to apply the principles of preventive medicine on a large scale. Municipalities thus consume large amounts of antiseptics in their health departments. Disinfecting compounds flood the market. They, however, vary widely in ability to kill the various pathogenic organisms. The use of scientific tests for disinfecting value is not widespread in this country, but their introduction and use would result in a saving to the municipality with increased surety of the effect of treatments. Scientific inspection of disinfectants is a subject which also touches the household. It should be placed on the same plane as food inspection. Use of an inefficient antiseptic will often lead to more serious conseproduct.

Fire authorities have recently directed their energies toward the prevention of fires rather than their extinguishment. To make sufficient and effective rules governing the use and transportation of combustibles and enforce them requires the advice and service of members of the chemical profession. Within recent years the widespread establishment of garages has greatly increased sewer explosions. Chemical investigation is required to control this problem and place the blame at the proper source. The ultimate solution of the difficulty rests on chemists working in collaboration with the plumbing and sanitation experts of departments having authority over the erection of buildings

Fireproofing and requirements in regard to it also occupy the attention of the latter departments. We owe our modern fire-resisting materials largely to the work of technologists in the chemistry of ceramics. The National Government has appreciated this fact, and now maintains a department of the Bureau of Standards for testing and research in ceramics.

A problem which has been given much thought and attention by municipal officers is the disposal of refuse, especially garbage. No satisfactory or altogether profitable method of disposal has been evolved. The treatment of this waste has not as yet been well studied by the chemist. The field of work, being comparatively unexplored, offers commensurate reward to members of the profession who shall bend their energies to the work. The most apparent method of increasing the value of garbage is that of rendering available the nitrogen of tankage, wh

Legal investigations have in many important instances been aided by the services of chemists. The opportunities for their work in this connection are more varied and numerous than have been realized. This leads to the beliei that the future will see a chemist with his microscope and laboratory attached to many police departments. His work will be not only the present wellknown toxicological investigation, but he will devise and apply delicate methods to the interpretation of clues which have in the past been closed books. The service rendered by that new branch of chemistry, metallography, is one instance of this. Boiler explosions have been difficult to trace to their origin, but microscopical examinations will often reveal faults in the heat treatment or structure of the metal which have caused disaster.

The foregoing outline suggests only a few of the possibilities for assistance that chemists may render our municipalities. An appreciation of the value of the science is necessary in the progressive civic official. Mor frequent attempts to throw the light of chemical research on problems will lead to satisfactory and even gratifying results. Surely the science of Liebig, Perkin and Bunsen can render increased aid to our American cities.

\section{Chinese Weights and Measures}

THE system of weights and measures in China is in an even more chaotic state than the currency and is characterized by the same lack of uniformity. The decimal system is used in theory but is not always adhered to in practice. The principal weights are $10 \mathrm{li}=1$ fên (candareen), 10 fên $=1$ ch'ien (mace), $10 \mathrm{ch}$ 'ien $=1$ liang (tael), 16 liang $=1$ chin (kin) or catty, 100 chin or catties $=1$ tan or picul. In native trade the catty ranges from 12 to 42.5 ounces, and the number of catties per picul varies from 90 to 280 . For purposes of foreign trade the customs authorities have fixed the liang, or tael, at $1 \frac{1 / 3}{3}$ ounces, or 583.3 grains, avoirdupois, the catty at $1 \frac{1 / 3}{3}$ pounds, and the picul at $1331 / 3$ pounds.

The measures of length are 10 fên $=1$ ts'un (inch) 10 ts'un $=1$ ch'ih (foot), 10 ch'ih $=1$ chong ( $p u$ or kung), 180 chong $=1 \mathrm{li}$. The ch'ih, or foot, varies from 8.6 to 27.8 inches in different parts of the country. For customs purposes it is fixed at 14.1 inches. In measuring cloth the foot used in some parts of China is sometimes 11.1 inches and sometimes 13.85 to 14.05 inches.

The principal measure of area is the mow, which is regarded at Shanghai as equal to one sixth of an English acre $(7,260$ square feet), but which varies throughout China from 3,840 to 9,964 square feet, with one standard of 18,140 square feet.-From Special Agents Series, No. 107, U. S. Department of Commerce. 